\title{
Parental influence on children's answers to an oral-health-related quality of life questionnaire
}

\begin{abstract}
Ana Flávia GRANVILLE-GARCIA Monalisa Cesarino GOMES Laíza Rocha DANTAS Lívia Rocha DANTAS Bruno Rafael Cruz da SILVA Matheus de França PERAZZO Maria Betânia Lins Dantas SIQUEIRA
\end{abstract}

Universidade Estadual da Paraíba - UEPB, Curso de Odontologia, Department of Dentistry, Campina Grande, PB, Brazil.

Declaration of Interests: The authors certify that they have no commercial or associative interest that represents a conflict of interest in connection with the manuscript.

Corresponding Author: Ana Flávia Granville-Garcia E-mail: anaflaviagg@hotmail.com

DOI: 10.1590/1807-3107BOR-2016.vol30.0014

Submitted: Mar 15, 2015

Accepted for publication: Aug 19, 2015

Last revision: Sep 24, 2015
Abstract: The aim of the study was to evaluate parental influence on children's answers to an oral health-related quality of life (OHRQoL) questionnaire. A cross-sectional study was conducted with a non-probabilistic sample of 84 pairs of 5 -year-olds and parents/guardians. The participants were selected from a primary family healthcare center in Campina Grande, Brazil. First, the children and parents answered respective versions of the Scale of Oral Health Outcomes for Five-Year-Old Children (SOHO-5). Seven days later, the children answered their version of the SOHO-5, without the presence of their parents/guardians, and underwent a clinical exam of dental caries, traumatic dental injury and malocclusion, by a previously calibrated researcher. Statistical analysis involved a comparison of mean scores and the calculation of the intraclass correlation coefficient (ICC). Poisson regression models were used to associate the variables $(\alpha=5 \%)$. No significant differences were found between the mean SOHO-5 scores of the children when alone or accompanied by parents/guardians $(\mathrm{p}>0.05)$. The ICC between the answers of the children alone or accompanied was 0.84 . White spot $(\mathrm{PR}=6.32$; 95\%CI: 1.36 - 29.40) and cavitated lesions (PR = 9.81; 95\%CI: 3.22 - 29.85) had an impact on OHRQoL, according to the children's self-report, whereas cavitated lesions ( $\mathrm{PR}=90.52 ; 95 \% \mathrm{CI}$ : 13.26 - 617.74) and anterior open bite (PR $=1.95$; 95\%IC: 1.07 - 3.53) remained on the final model, according to the parents' version of the SOHO-5. In conclusion, parents did not influence the children's responses, and dental caries are the oral health problem exerting the greatest impact on the children's OHRQoL.

Keywords: Quality of Life; Parents; Child, Preschool.

\section{Introduction}

Oral health problems, such as dental caries, traumatic dental injury (TDI) and malocclusion are common among preschool children. ${ }^{1,2}$ The concept of oral-health-related quality of life (OHRQoL) addresses the impact of oral health problems on daily functioning and well-being. However, the development of OHRQoL measures for young children is challenging, due to their limited cognitive and emotional development and to social contexts. ${ }^{3,4}$

There are few OHRQoL measures for preschool children., ${ }^{4,5}$ The relatively limited research in this respect is a consequence of conceptual 
challenges in the development of such measures for young children. Two measures have been validated and adapted for Brazilian Portuguese: the Early Childhood Oral Health Impact Scale (ECOHIS) and the Scale of Oral Health Outcomes for Five-Year-Old Children (SOHO-5), ${ }^{6,7}$ However, the ECOHIS is based only on parental proxy reports. ${ }^{5,6}$ Although such proxy measures are commonly employed, parents/guardians do not always perceive the OHRQoL of their children accurately. Thus, parental proxy reports may offer a different perception, but should not be used alone, without the self-reports of children., ${ }^{4,8}$

Studies involving the SOHO-5 that evaluate the perception of parents/guardians and children have demonstrated that five-year-old children are capable of providing their own perceptions regarding their OHRQoL. 4,7,9,10,11 However, their comprehension is dependent on social, emotional, cognitive and linguistic development. ${ }^{12}$ Moreover, children in this age group are influenced by their parents/guardians, who are the main decision makers regarding healthcare issues. ${ }^{13}$ Thus, it is important to evaluate how influential the presence of parents/guardians is when children answer a OHRQoL questionnaire. Previous studies evaluating the perception of children regarding their OHRQoL have not clarified this issue. ${ }^{4,79,10,11}$

The aim of the present study was to evaluate how the presence of parents/guardians influences the answers to an OHRQoL questionnaire directed at five-year-old preschool children.

\section{Methodology}

\section{Sample characteristics}

A cross-sectional study was conducted with a non-probabilistic sample from a primary family healthcare center in Campina Grande, Brazil, an industrialized city with an estimated population of 402,912 inhabitants, and divided into six administrative districts. The city has significant cultural, social and economic inequality, with an average per capita income of US\$110, a Human Development Index of 0.72 and a poverty rate of $58.88 \%{ }^{14}$ All children aged five years and parents/guardians seeking treatment for these children at the primary healthcare center between January and April 2014 were recruited for the study $(\mathrm{n}=84)$.

\section{Ethical considerations}

This study received approval from the Human Research Ethics Committee of the Universidade Estadual da Paraíba - UEPB (Brazil) under process number 25186813.6.0000.5187. The study was conducted in accordance with the Declaration of Helsinki and Resolution 466/12 of the Conselho Nacional de Saúde - CNS (Brazilian National Board of Health). Parents/caregivers read and signed a statement of informed consent prior to the children's participation.

\section{Eligibility criteria}

The eligibility criteria were children five years of age in the primary dentition phase, no history of orthodontic treatment and free of systemic diseases (based on the reports of their parents/guardians).

\section{Training and calibration exercise}

The training and calibration exercise consisted of two phases. The theoretical phase involved a discussion of the criteria for the diagnosis of dental caries, TDI and malocclusion, as well as an analysis of photographs. A specialist in pediatric dentistry coordinated this phase, instructing a general dentist on how to perform the examination. The dentist examined 20 preschool children. Data analysis involved the calculation of Cohen's Kappa (K) coefficient on a tooth-by-tooth basis. Interexaminer agreement was tested by comparing the examiner with the gold standard for dental caries ( $\mathrm{K}=0.87)$, TDI $(\mathrm{K}=0.80)$ and malocclusion $(K=0.82)$. Seven days later, the examinations were performed a second time to determine intraexaminer agreement for dental caries $(\mathrm{K}=0.88)$, TDI $(\mathrm{K}=0.89)$ and malocclusion $(\mathrm{K}=0.89)$. The examiner was considered capable of conducting the study, based on the very good Kappa coefficients. ${ }^{15}$ The preschool children examined in the calibration exercises did not participate in the main study.

\section{Pilot study}

A pilot study was conducted to test the methodology. The participants in the pilot study $(n=20)$ were selected from a referral health center and not included in the 
main sample. At this stage of the study, the dynamics of the data collection were evaluated for the application of the questionnaires and the clinical examination of the children. Since there were no misunderstandings regarding the methodology, no changes to the data collection process were deemed necessary.

\section{Study procedures}

The sample was taken from a screening for dental treatment. The child and one of the guardians (preferably the one who spent the most time with the child) completed the Brazilian SOHO-5 in face-to-face interviews. ${ }^{7}$ The interviews were conducted by two trained interviewers blinded to the clinical findings. The child and the guardian answered the respective child and parental versions of the SOHO-5 in the presence of each other. Seven days later, the children answered the child version of the questionnaire a second time without the presence of the parents/guardians, and a dental examination was performed on the same day.

\section{Non-clinical data collection}

The Brazilian version of the $\mathrm{SOHO}-5$ addresses a child's lifetime experience with oral impacts ${ }^{4,7}$ and has two (child and parental) seven-item scales, six of which are common in content. The seven items on the child's self-report scale are difficulty eating, difficulty drinking, difficulty speaking, difficulty playing, difficulty sleeping, avoiding smiling due to pain and avoiding smiling due to appearance. The response options are assessed according to a three-point scale (no $=0$, a little $=1$ and a lot $=2$ ), aided by an explanation card with corresponding faces. The seven items of the parental version are difficulty eating, difficulty speaking, difficulty playing, difficulty sleeping, avoiding smiling due to pain, avoiding smiling due to appearance and affected self-confidence of the child. The response options are stated on a five-point scale (no $=0$, a little $=1$, moderate $=2$, a lot $=3$ and a great deal $=4$ ). The total score for each version is calculated as a simple sum of the response codes. Since there were seven questions, the final score ranges from 0 to 14 for the child version and 0 to 28 for the parental version. A higher score denotes a greater degree of oral impact on the quality of life of the child.

\section{Clinical data collection}

After obtaining the signed statement of informed consent and upon completion of the questionnaires, clinical examinations were performed by a properly calibrated dentist. Prophylaxis was first performed by removing bacterial plaque from the child's teeth. The child was then seated in the dental chair. The dentist used individual protection equipment, a sterile mouth mirror (Prisma ${ }^{\circledR}$, São Paulo, Brazil) and a sterile Williams probe (WHO-621, Trinity ${ }^{\circledR}$, Campo Mourão, Brazil).

Dental caries was diagnosed using the International Caries Detection and Assessment System (ICDAS II), which is a scoring system ranging from 0 (absence of dental caries) to 6 . Code 2 was used for white spots, and codes $\geq 3$ determined different degrees of cavitation. ${ }^{16}$ This variable was categorized by considering the most serious lesion suffered by the child.

TDI was diagnosed as enamel fracture, enamel + dentine fracture, complicated crown fracture, extrusive luxation, lateral luxation, intrusive luxation and avulsion. ${ }^{17}$ A visual inspection of tooth coloration was also made. TDI diagnosis was performed on the upper and lower canines and incisors. TDI was recorded in the presence of any type of TDI or tooth discoloration. For statistical analysis, TDI was dichotomized into absent, non-complicated TDI (enamel fracture and enamel + dentine fracture), complicated TDI (complicated crown fracture, luxation and avulsion) and tooth discoloration. Malocclusion was recorded in the presence of at least one of the following conditions: increased overbite (> $2 \mathrm{~mm})$, increased overjet ( $>2 \mathrm{~mm}$ ), anterior open bite, anterior crossbite and posterior crossbite. ${ }^{18,19}$ After undergoing the clinical exam, children with dental needs were sent for treatment.

\section{Statistical analysis}

Descriptive statistics were performed to characterize the sample. Agreement between the answers of the children alone or accompanied was assessed by comparing mean $\mathrm{SOHO}-5$ scores (Wilcoxon test) and calculating the intraclass correlation coefficient (ICC). 
The level of agreement of the ICC was categorized as follows: $<0.2=$ poor; 0.2 to $0.40=$ fair; 0.41 to $0.60=$ moderate; 0.61 to $0.80=$ substantial; and 0.81 to $1.0=$ excellent to perfect..$^{10}$ The Mann-Whitney and Kruskal-Wallis tests were used to determine associations between oral health conditions and the mean SOHO- 5 for total and item scores on the child and parental scales. Poisson Regression analysis with robust variance was performed to correlate the total $\mathrm{SOHO}-5$ scores with the independent variables. The backward stepwise method was used for the selection of variables with a p-value $<0.20$ in the bivariate analysis. Variables with a p-value $<0.05$ in the adjusted analysis were maintained in the final regression model. The data were organized and analyzed with the aid of the Statistical Package for Social Sciences (SPSS for Windows, version 20.0, SPSS Inc., Chicago, USA).

\section{Results}

Eighty-four pairs of children and parents/guardians participated in the present study. No losses occurred due to incomplete questionnaires, and all of the parents agreed to participate in the study. A total of $65.5 \%$ of the children were diagnosed with dental caries, $28.6 \%$ were diagnosed with TDI, and 51.2\% had some type of malocclusion.

Table 1 displays the mean $\mathrm{SOHO}-5$ total and item scores. No significant difference was found between the scores of the children with or without the presence of their parents/guardians ( $p>0.05)$. The ICC for the total scores of the children with or without the presence of their parents/guardians was $0.84(0.75-0.89)$. The ICC values for the items ranged from 0.79 (difficulty eating) to 0.61 (difficulty speaking), with $\mathrm{p}<0.001$ (Table 2).

According to both the self-reported and parental versions of the scale, OHRQoL was poorer among children with dental caries $(\mathrm{p}<0.001)$. On the child scale, significant associations were found between dental caries and the items: difficulty eating, difficulty speaking, difficulty playing, difficulty sleeping and difficulty drinking. On the parental scale, significant associations were found between dental caries and the items: difficulty eating, difficulty playing and difficulty sleeping. Malocclusion was significantly associated with difficulty drinking (child scale), difficulty eating (parental scale) and difficulty playing (parental scale) $(p<0.05)$. No significant associations were found with TDI (Table 3 ).

Following bivariate and multivariate Poisson regression analysis, the white spot $(\mathrm{PR}=6.32$; $95 \%$ CI: 1.36 - 29.40) and cavitated lesion variables (PR $=9.81 ; 95 \% C I$ : 3.22 - 29.85) were associated with a negative impact on the OHRQoL of the children, according to their own reports. According to the version of the parents/guardians, however, the cavitated lesion ( $\mathrm{PR}=90.52$; 95\%CI: 13.26 - 617.74) and anterior open bite variables ( $\mathrm{PR}=1.95$; 95\%CI: 1.07 -3.53) remained on the final model (Table 4).

\section{Discussion}

The Brazilian version of the $\mathrm{SOHO}-5$ has proven to be valid, reliable, reproducible and responsive to change. ${ }^{7,9}$ Moreover, children have demonstrated the ability to understand the questionnaire appropriately. ${ }^{4}$

Table 1. Mean SOHO-5 and items scores of children with and without presence of parents/guardians.

\begin{tabular}{|c|c|c|c|}
\hline & Child in presence of parent/guardian & Child without presence of parent/guardian & \\
\hline & Mean (SD) & Mean (SD) & p-value* \\
\hline Total score & $2.23(2.70)$ & $2.38(3.45)$ & 0.829 \\
\hline Difficulty eating & $0.56(0.81)$ & $0.60(0.80)$ & 0.424 \\
\hline Difficulty drinking & $0.42(0.62)$ & $0.51(0.68)$ & 0.123 \\
\hline Difficulty speaking & $0.19(0.52)$ & $0.17(0.48)$ & 0.714 \\
\hline Difficulty playing & $0.21(0.53)$ & $0.26(0.62)$ & 0.408 \\
\hline Difficulty sleeping & $0.32(0.66)$ & $0.29(0.68)$ & 0.666 \\
\hline Avoid smiling due to appearance & $0.25(0.59)$ & $0.29(0.66)$ & 0.580 \\
\hline Avoid smiling due to pain & $0.27(0.60)$ & $0.27(0.62)$ & 0.976 \\
\hline
\end{tabular}

${ }^{*} p$-value derived from Wilcoxon test $(p<0.05)$. 
Table 2. Correlations between $\mathrm{SOHO}-5$ total and item scores with without presence of parent/guardian.

\begin{tabular}{lcc}
\hline & $\begin{array}{c}\text { Child with presence of parent/guardian versus child alone } \\
\text { Intraclass correlation coefficient (95\% CI) }\end{array}$ & p-value* \\
\hline Total score & $0.84(0.75-0.89)$ & $<0.001$ \\
Difficulty eating & $0.79(0.68-0.86)$ & $<0.001$ \\
Difficulty drinking & $0.78(0.66-0.85)$ & $<0.001$ \\
Difficulty speaking & $0.61(0.40-0.74)$ & $<0.001$ \\
Difficulty playing & $0.64(0.44-0.76)$ & $<0.001$ \\
Difficulty sleeping & $0.74(0.60-0.83)$ & $<0.001$ \\
Avoiding smiling due to appearance & $0.72(0.57-0.82)$ & $<0.001$ \\
Avoiding smiling due to pain & $0.76(0.64-0.85)$ & $<0.001$ \\
\hline
\end{tabular}

${ }^{*} p<0.001$

Table 3. Mean SOHO-5 total and item scores according to dental caries, TDI and malocclusion.

\begin{tabular}{|c|c|c|c|c|c|c|c|c|}
\hline & $\begin{array}{l}\text { Difficulty } \\
\text { eating }\end{array}$ & $\begin{array}{l}\text { Difficulty } \\
\text { speaking }\end{array}$ & $\begin{array}{l}\text { Difficulty } \\
\text { playing }\end{array}$ & $\begin{array}{l}\text { Difficulty } \\
\text { sleeping }\end{array}$ & $\begin{array}{l}\text { Avoiding smiling } \\
\text { due to appearance }\end{array}$ & $\begin{array}{l}\text { Avoiding smiling } \\
\text { due to pain }\end{array}$ & $\begin{array}{l}\text { Difficulty } \\
\text { drinking }\end{array}$ & $\begin{array}{l}\text { Mean total } \\
\text { score }\end{array}$ \\
\hline \multicolumn{9}{|c|}{ Child self-report version* } \\
\hline \multicolumn{9}{|l|}{ Dental caries } \\
\hline Absent & $0.14(0.51)^{a}$ & $0.00(0.00)^{a}$ & $0.00(0.00)^{a}$ & $0.03(0.18)^{a}$ & $0.03(0.71)$ & $0.07(0.37)$ & $0.03(0.18)^{a}$ & $0.31(0.93)^{\circ}$ \\
\hline White spot & $0.00(0.00)^{a}$ & $0.50(0.75)^{b}$ & $0.25(0.70)^{b, a}$ & $0.50(0.75)^{b}$ & $0.25(0.70)$ & $0.25(0.46)$ & $0.38(0.74)^{b}$ & $2.13(3.60)^{\mathrm{b}}$ \\
\hline Cavity & $0.91(0.85)^{b}$ & $0.26(0.60)^{b}$ & $0.34(0.63)^{\mathrm{b}}$ & $0.47(0.77)^{b}$ & $0.38(0.70)$ & $0.40(0.71)$ & $0.66(0.66)^{b}$ & $3.43(2.63)^{\mathrm{b}}$ \\
\hline $\mathrm{p}$-value** & $<0.001^{* *}$ & $0.012^{* *}$ & $0.013^{* *}$ & $0.012^{* *}$ & 0.041 & 0.037 & $<0.001^{* *}$ & $<0.001^{* *}$ \\
\hline \multicolumn{9}{|l|}{ TDI } \\
\hline Absent & $0.57(0.81)$ & $0.20(0.54)$ & $0.25(0.57)$ & $0.40(0.71)$ & $0.27(0.60)$ & $0.30(0.61)$ & $0.42(0.61)$ & $2.40(2.66)$ \\
\hline Present & $0.54(0.83)$ & $0.17(0.48)$ & $0.13(0.44)$ & $0.13(0.44)$ & $0.21(0.58)$ & $0.21(0.58)$ & $0.42(0.65)$ & $1.79(2.81)$ \\
\hline$p$-value*** & 0.843 & 0.892 & 0.267 & 0.068 & 0.556 & 0.381 & 0.934 & 0.173 \\
\hline \multicolumn{9}{|l|}{ Malocclusion } \\
\hline Absent & $0.37(0.62)$ & $0.17(0.49)$ & $0.24(0.58)$ & $0.34(0.65)$ & $0.27(0.59)$ & $0.24(0.58)$ & $0.24(0.48)$ & $1.88(2.70)$ \\
\hline Present & $0.74(0.92)$ & $0.21(0.55)$ & $0.19(0.50)$ & $0.30(0.67)$ & $0.23(0.61)$ & $0.30(0.63)$ & $0.58(0.69)$ & $2.56(2.70)$ \\
\hline$p$-value ${ }^{* * *}$ & 0.077 & 0.795 & 0.675 & 0.600 & 0.562 & 0.652 & $0.014^{* * *}$ & 0.110 \\
\hline \multicolumn{9}{|l|}{ Parental version } \\
\hline \multicolumn{9}{|l|}{ Dental caries } \\
\hline Absent & $0.03(0.18)^{a}$ & $0.00(0.00)$ & $0.00(0.00)^{a}$ & $0.00(0.00)^{a}$ & $0.00(0.00)$ & $0.00(0.00)$ & $0.00(0.00)$ & $0.00(0.00)^{\circ}$ \\
\hline White spot & $0.13(0.35)^{a}$ & $0.00(0.00)$ & $0.00(0.00)^{a, b}$ & $0.00(0.00)^{a}$ & $0.00(0.00)$ & $0.00(0.00)$ & $0.00(0.00)$ & $0.13(0.35)^{\circ}$ \\
\hline Cavity & $1.32(1.25)^{\mathrm{b}}$ & $0.19(0.77)$ & $0.34(0.60)^{b}$ & $1.04(1.21)^{b}$ & $0.34(0.98)$ & $0.30(0.80)$ & $0.23(0.78)$ & $3.77(4.10)^{b}$ \\
\hline $\mathrm{p}$-value** & $<0.001^{* *}$ & 0.298 & $0.003^{* *}$ & $<0.001^{* *}$ & 0.081 & 0.032 & 0.127 & $<0.001^{* *}$ \\
\hline \multicolumn{9}{|l|}{ TDI } \\
\hline Absent & $0.86(1.23)$ & $0.15(0.69)$ & $0.20(0.51)$ & $0.68(1.13)$ & $0.27(0.88)$ & $0.24(0.72)$ & $0.19(0.70)$ & 2.59 (4.01) \\
\hline Present & $0.50(0.83)$ & $0.00(0.00)$ & $0.17(0.38)$ & $0.38(0.77)$ & $0.00(0.00)$ & $0.00(0.00)$ & $0.00(0.00)$ & 1.04 (1.89) \\
\hline$p$-value ${ }^{* * *}$ & 0.227 & 0.268 & 0.949 & 0.251 & 0.110 & 0.062 & 0.147 & 0.062 \\
\hline \multicolumn{9}{|l|}{ Malocclusion } \\
\hline Absent & $0.49(0.95)$ & $0.10(0.62)$ & $0.10(0.37)$ & $0.44(0.97)$ & $0.27(0.92)$ & $0.20(0.71)$ & $0.20(0.71)$ & 1.78 (3.65) \\
\hline Present & $1.02(1.25)$ & $0.12(0.55)$ & $0.29(0.55)$ & $0.74(1.10)$ & $0.12(0.55)$ & $0.14(0.52)$ & $0.07(0.46)$ & $2.50(3.54)$ \\
\hline$p$-value ${ }^{* * *}$ & $0.021^{* * *}$ & 0.607 & $0.043^{* * *}$ & 0.179 & 0.362 & 0.916 & 1.59 & 1.35 \\
\hline
\end{tabular}

*Version of questionnaire applied to children first, in the presence of parents/guardians.

**Kruskal-Wallis test with Bonferroni correction ( $<<0.016$ ); Values expressed as mean (standard deviation); Different superscript letters indicate significant differences between categories for the same SOHO-5 item $(p<0.05)$.

***Mann-Whitney test $(p<0.05)$. 
- Parental influence on children's answers to an oral-health-related quality of life questionnaire

Table 4. Poisson regression analysis between oral health problems and total SOHO-5 point score according to children and parents.

\begin{tabular}{|c|c|c|c|c|c|}
\hline & \multirow{2}{*}{$\begin{array}{l}\text { Mean total } \\
\text { score }\end{array}$} & \multicolumn{2}{|c|}{ Bivariate / Unadjusted PR } & \multicolumn{2}{|c|}{ Multivariate / Adjusted PR } \\
\hline & & (95\%Cl) & $p$-value & (95\%Cl) & $\mathrm{p}$-value \\
\hline \multicolumn{6}{|l|}{ Child self-report version* } \\
\hline \multicolumn{6}{|l|}{ Dental caries } \\
\hline Absent & $0.31(0.93)$ & 1.00 & & 1.00 & \\
\hline White spots & $2.13(3.60)$ & $6.84(1.47-31.77)$ & 0.014 & $6.32(1.36-29.40)$ & 0.019 \\
\hline Cavitation & $3.43(2.63)$ & $11.03(3.69-32.93)$ & $<0.001$ & 9.81 (3.22 - 29.85) & $<0.001$ \\
\hline \multicolumn{6}{|l|}{ TDI } \\
\hline No trauma & $2.40(2.66)$ & 1.00 & & - & - \\
\hline Uncomplicated TDI & $1.19(1.83)$ & $0.49(0.24-1.00)$ & 0.050 & - & - \\
\hline Complicated TDI & $3.00(0.0)$ & $1.25(0.94-1.65)$ & 0.117 & - & - \\
\hline Tooth discoloration & $7.50(6.36)$ & $3.12(1.30-7.51)$ & 0.011 & - & - \\
\hline \multicolumn{6}{|l|}{ Malocclusion } \\
\hline Present & $2.56(2.70)$ & $1.36(0.79-2.32)$ & 0.258 & - & - \\
\hline Absent & $1.88(2.70)$ & 1.00 & & - & - \\
\hline \multicolumn{6}{|l|}{ Anterior open bite } \\
\hline Present & $2.67(1.78)$ & $1.28(0.81-2.02)$ & 0.280 & - & - \\
\hline Absent & $2.08(2.92)$ & 1.00 & & - & - \\
\hline \multicolumn{6}{|l|}{ Parental version } \\
\hline \multicolumn{6}{|l|}{ Dental caries } \\
\hline Absent & $0.03(0.18)$ & 1.00 & & 1.00 & \\
\hline White spots & $0.13(0.35)$ & $3.62(0.25-51.77)$ & 0.342 & $2.84(0.21-37.04)$ & 0.429 \\
\hline Cavitation & $3.77(4.10)$ & $109.21(15.53-767.90)$ & $<0.001$ & $90.52(13.26-617.74)$ & $<0.001$ \\
\hline \multicolumn{6}{|l|}{ TDI } \\
\hline No trauma & $2.57(3.98)$ & 1.00 & & - & - \\
\hline Uncomplicated TDI & $0.86(1.79)$ & $0.33(0.12-0.87)$ & 0.025 & - & - \\
\hline Complicated TDI & $2.00(0.0)$ & $0.77(0.52-1.15)$ & 0.210 & - & - \\
\hline Tooth discoloration & $2.50(3.53)$ & $0.97(0.23-4.11)$ & 0.971 & - & - \\
\hline \multicolumn{6}{|l|}{ Malocclusion } \\
\hline Present & $2.47(3.51)$ & $1.38(0.65-2.92)$ & 0.395 & - & - \\
\hline Absent & $1.78(3.65)$ & 1.00 & & - & - \\
\hline \multicolumn{6}{|l|}{ Anterior open bite } \\
\hline Present & $4.17(4.42)$ & $14.28(1.71-119.16)$ & 0.014 & $1.95(1.07-3.53)$ & 0.027 \\
\hline Absent & 1.51 (3.09) & 1.00 & & 1.00 & \\
\hline
\end{tabular}

*Version of questionnaire applied to children first, in the presence of parents/guardians.

The present results show that the answers of children on the SOHO-5 were not influenced by the presence of their parents/guardians.

Although parenting styles are a result of a parent's attitudes, beliefs and behaviors, and establish the emotional context for the child, ${ }^{20}$ the mean SOHO-5 total and item scores did not differ significantly when the children were alone or accompanied. Excellent correlation was found among the total scores, and substantial correlations were found for the item scores, demonstrating that five-year-old children are perfectly able to report their own OHRQoL, ,21 regardless of the presence of their parents/guardians. However, it is important that the proxy measure of parents/guardians be considered together with the self-report of children, since children may not be reliable with regard to some psychosocial domains, ${ }^{4}$ and most likely have difficulty understanding emotions that require greater cognitive development. Thus, parental reports provide valuable information in their own right, ${ }^{10}$ and the parental scale of the SOHO-5 should be considered along with the child 
version for complete evaluation of the OHRQoL of young children.

With respect to oral health problems, only dental caries demonstrated a significant impact on OHRQoL. Previous studies have also found this to be the main oral health problem in this age group, leading to functional, psychological and social problems, whether determined by self-reports or proxy measures. ${ }^{1,2,10,22}$ Indeed, both the mean SOHO-5 total and item scores were greater among children with dental caries, in agreement with previous study data. ${ }^{7,10,11}$ It was noted that, in addition to cavitated lesions, white spots were associated with OHRQoL for some items and in the multivariate model for the child version. The reason could be that these spots cause aesthetic discomfort, which may impact social interaction and the child's self-image. Consequently, they may interfere with the daily activities of the child, particularly when the spots occur in anterior teeth. In this study, most of the white spot lesions were observed only in the anterior teeth. In cases of white spot lesions in the posterior teeth, these were associated with the concomitant presence of the same lesions in the anterior teeth.

TDI was not significantly associated with the mean total scores. These findings are likely due to the greater prevalence of non-complicated TDI, ${ }^{23}$ which may have influenced the results. Nonetheless, some SOHO-5 items were significantly associated with malocclusion and difficulty drinking on the child scale, and difficulty eating and difficulty playing on the parental scale, perhaps because difficulty playing plays an important role in the social interaction of

\section{References}

1. Scarpelli AC, Paiva SM, Viegas CM, Carvalho AC, Ferreira FM, Pordeus IA. Oral health-related quality of life among Brazilian preschool children. Community Dent Oral Epidemiol. 2013;41(4):336-44.doi:10.1111/cdoe.12022

2. Gomes MC, Pinto-Sarmento TC, Costa EM, Martins CC, Granville-Garcia AF, Paiva SM. Impact of oral health conditions on the quality of life of preschool children and their families: a cross-sectional study. Health Qual Life Outcomes. 2014;12:55. doi: 10.1186/1477-7525-12-55 children. ${ }^{22}$ Multivariate analysis found an association between anterior open bite and OHRQoL according to the parental version. A previous study found that anterior open bite was negatively associated with the function domain, according to the perception of parents. ${ }^{24}$ Moreover; parents of children with anterior open bite are more likely to categorize the oral health of their child as poor. ${ }^{25}$

The evaluation of how oral health problems impact OHRQoL should be made with validated measures and detailed methods. The analysis of the present findings demonstrates that the presence of parents/guardians does not influence the children's answers. However, the present study used a convenience sample taken from a screening for dental treatment. The broad confidence interval of the multivariate model may be considered a limitation of the present study. However, it may be precise enough to allow decisions to be made about how useful an intervention may be. This factor may account for some heterogeneity in the sample. ${ }^{26}$ Further studies with representative samples are needed to analyze the impact of oral health problems on OHRQoL, based on the children's self-reports, and will enable the establishment of public health policies aimed at improving the OHRQoL of target populations.

\section{Conclusion}

The presence of parents/guardians does not influence the answers of five-year-old children to an oral health-related quality of life questionnaire. Moreover, dental caries demonstrated poorer OHRQoL on both the self-reported and parental scales.

3. Eiser C, Mohay H, Morse R. The measurement of quality of life in young children. Child Care Health Dev. 2000;26(5):401-13. doi: 10.1046/j.1365-2214.2000.00154.x

4. Tsakos G, Blair YI, Yusuf H, Wright W, Watt RG, Macpherson LM. Developing a new self-reported scale of oral health outcomes for 5-year-old children (SOHO-5). Health Qual Life Outcomes. 2012;10:62. doi: 10.1186/1477-7525-10-62

5. Pahel BT, Rozier RG, Slade GD. Parental perceptions of children's oral health: The Early Childhood Oral Health Impact Scale (ECOHIS). Health Qual Life Outcomes. 2007 Jan 30;5:6. doi: 10.1186/1477-7525-5-6 
6. Tesch FC, Oliveira BH, Leão A. Semantic equivalence of the Brazilian version of the Early Childhood Oral Health Impact Scale. Cad Saude Publica. 2008;24(8):1897-909. Portuguese. doi: 10.1590/S0102-311X2008000800018

7. Abanto J, Tsakos G, Paiva SM, Goursand D, Raggio DP, Bonecker M. Cross-cultural adaptation and psychometric properties of the Brazilian version of the Scale of Oral Health Outcomes for-5-year-old children (SOHO-5). Health Qual Life Outcomes. 2013;11:16. doi: 10.1186/1477-7525-11-16

8. Theunissen NCM, Vogels TGC, Koopman HM, Verrips GHW, Zwinderman KAH, Verloove-Vanhorick SP, et al. The proxy problem: child report versus parent report in health-related quality of life research. Qual Life Res. 1998;7(5):387-97.

9. Abanto J, Tsakos G, Ardenghi TM, Paiva SM, Raggio DP, Sheiham A, et al. Responsiveness to change for the Brazilian Scale of Oral Health Outcomes for 5-year-old children (SOHO-5). Health Qual Life Outcomes. 2013;11:137. doi: 10.1186/1477-7525-11-137

10. Abanto J, Tsakos G, Paiva SM, Carvalho TS, Raggio DP, Bonecker M. Impact of dental caries and trauma on quality of life among 5- to 6-year-old children: perceptions of parents and children. Community Dent Oral Epidemiol. 2014 Oct;42(5):385-94. doi: 10.1111/cdoe.12099.

11. Abanto J, Tello G, Bonini GC, Oliveira LB, Murakami C, Bönecker M. Impact of traumatic dental injuries and malocclusions on quality of life of preschool children: a population-based study. Int J Paediatr Dent. 2015;25(1):18-28. doi: 10.1111/ipd.12092

12. Matza LS, Swensen AR, Flood EM, Secnik K, Leidy NK. Assessment of health-related quality of life in children: a review of conceptual, methodological, and regulatory issues. Value Health. 2004;7(1):79-92.

13. Talekar BS, Rozier RG, Slade GD, Ennett ST. Parental perceptions of their preschool-aged children's oral health. J Am Dent Assoc. 2005 Mar;136(3):364-72; quiz 381.

14. Instituto Brasileiro deGeografia e Estatística [homepage]. Brasília (DF): Instituto Brasileiro deGeografia e Estatística; 2015 [cited 2015 Jan18]. Avaliablefrom:http://cidades.ibge.gov.br/xtras/home.php

15. Altman DG. Practical statistics for medical research. 2nd ed. London (England): Chapman and Hall; 2006.

16. Ismail A I, Sohn W, Tellez M, Amaya A, Sen A, Hasson H, et al. The International Caries Detection and Assessment System (ICDAS): an integrated system for measuring dental Caries. Community Dent Oral Epidemiol. 2007;35(3):170-8. doi: 10.1111/j.1600-0528.2007.00347.x
17. Andreasen JO, Andreasen FM, Andersson L. Textbook and color atlas of traumatic injuries to the teeth. 4 th ed. Oxford: Blackwell; 2007.

18. Foster TD, Hamilton MC. Occlusion in the primary dentition. Study of children at 2 and one-half to 3 years of age. Br Dent J. 1969;126(2):76-9.

19. Grabowski R, Stahl F, Gaebel M, Kundt G. Relationship between occlusal findings and orofacial myofunctional status in primary and mixed dentition. Part I: Prevalence of malocclusions. J Orofac Orthop. 2007;68(1):26-37.

20. Philips N, Sioen I, Michels N, Sleddens E, De Henauw S. The influence of parenting style on health related behavior of children: findings from the ChiBS study. Int J Behav Nutr Phys Act. 2014;11:95. doi: 10.1186/s12966-014-0095-y

21. Varni JW, Seid M, Kurtin PS. PedsQL" 4.0: reliability and validity of the Pediatric Quality of Life Inventory version 4.0 generic core scales in healthy and patient populations. Med Care. 2001;39(8):800-12.

22. Kramer PF, Feldens CA, Ferreira SH, Bervian J, Rodrigues PH, Peres MA. Exploring the impact of oral diseases and disorders on quality of life of preschool children. Community Dent Oral Epidemiol. 2013;41(4):327-35. doi: 10.1111/cdoe.12035.

23. Aldrigui JM, Abanto J, Carvalho TS, Mendes FM, Wanderley MT, Bonecker M, et al. Impact of traumatic dental injuries and malocclusions on quality of life of young children. Health Qual Life Outcomes. 2011 Sep;9:78. doi: 10.1186/1477-7525-9-78

24. Goettems ML, Ardenghi TM, Romano AR, Demarco FF, Torriani DD. Influence of maternal dental anxiety on oral health-related quality of life of preschool children. Qual Life Res. 2011;20(6):951-9. doi: 10.1007/s11136-010-9816-0.

25. Piovesan C, Marquezan M, Kramer PF, Bonecker M, Ardenghi TM. Socioeconomic and clinical factors associated with caregivers' perceptions of children's oral health in Brazil. Community Dent Oral Epidemiol. 2011;39(3):260-7. doi: 10.1111/j.1600-0528.2010.00598.x.

26. Higgins JPT, Green S, editors. Cochrane handbook for systematic reviews of interventions version 5.1.0 [Internet]. [place unknown]: The Cochrane Collaboration; 2011 [cited 2015 Mar 20]. Available from: http://www.cochrane-handbook.org 